\title{
Appraisal of Biocidal Effectivity of Some Selected Biochemical and Chemical Formulations against Helicoverpa Armigera (Hubner) in Tomato Crop
}

\author{
Khan RR 1,2*, Shaheen T1, Majeed S1, Ali A', Arshad M11, AlMazidi \\ ISS 2 and AlGhafri THA ${ }^{2}$ \\ ${ }^{1}$ Department of Entomology, University of Agriculture, Pakistan \\ 2Department of Plant Protection, Directorate General of Agriculture and Livestock \\ Research, Sultanate of Oman
}

\section{Research Article \\ Volume 2 Issue 2}

Received Date: February 01, 2019

Published Date: March 04, 2019

DOI: $10.23880 /$ izab-16000138

*Corresponding author: Rashad Rasool Khan, Department of Plant Protection, Directorate General of Agriculture and Livestock Research, Ministry of Agriculture and Fisheries, Sultanate of Oman, Tel: 00968 71119076; Email: rashadkhan@uaf.edu.pk

\section{Abstract}

A large number of field crops are consumed by the Tomato Fruit Borer (TFB), Helicoverpa armigera (Hubner) due to its polyphagous behavior. This insect has been reported notorious for causing economic losses in the tomato crop. Chemicals are being used in tomato fields for quick and effective control. Therefore, field trials were performed to evaluate the comparative effectivity of some newer chemical insecticides viz., chlorfenapyr (Pirate ${ }^{\circ}$ 360SL), chlorantraniliprole (Coragen $\AA$ 20SC), flubendiamide (Belt ${ }^{\circledR}$ 480SC) and bio-chemical insecticides viz., emamectin benzoate (Proclaim ${ }^{\circledR}$ 1.9EC) and spinosad (Tracer® 240SC) against TFB in the tomato crop. Recommended field rates as provided on the label by the manufacturers were applied under the field conditions. As a result, the insecticide formulation flubendiamide proved to be more effective until the 9 th day of insecticidal spray by reducing the pest population up to $92.00 \pm 1.74 \%$ and $90.02 \pm 1.74 \%$ after 1st and 2nd insecticidal spray, respectively. However, emamectin benzoate (Proclaim 1.9EC) remained least effective among the selected insecticides and lowest values of $80.02 \pm 1.17$ and $81.02 \pm 1.70 \%$ pest reduction were observed after the both spray. None of the insecticide proved to be non-effective against TFB under the field conditions. Hence, these insecticides can be best suited in the IPM program for the pest control.

Keywords: Insecticides; Efficacy; Helicoverpa Armigera; Tomatoes

Abbreviations: TFB: Tomato Fruit Borer; GABA: Gamma-amino-butyric acid; RyR: Ryanodine Receptor; nAChRs: Nicotinic Acetylcholine Receptors; AARI: Ayub
Agricultural Research Institute; ETL: Economic Threshold Level; RCBD: Randomized Complete Block Design. 


\section{International Journal of Zoology and Animal Biology}

\section{Introduction}

Tomato, Lycopersicum esculentum Miller belonging to the Solanaceae family, is the second most important vegetable crop all over the world after potato [1]. It covered an area of 63200 hectares with 599700 tons of production in the year 2013-14 [2]. A wide variety of insects contribute as one of the major limiting factor in attaining the higher tomato yield by the farmers due to their attack on tomato plant and fruit. Among these insect pests, the tomato fruit borer (hereafter read as TFB), Helicoverpa armigera Hubner (Lepidoptera: Noctuidea) is reported to be the most noxious and destructive insect pest worldwide causing serious losses in tomato yield ranging between 20 to 60 percent $[3,4]$. Yield losses caused by TFB in tomato field have been reported by different scientists in India as $5-155 \%$ and $37.79 \%$ while $35 \%$ and $53 \%$ in Pakistan [5-8].

The economic significance and growing market demands of tomato developed a challenging management to get higher yields by the farmers and hence they started inadvisable spraying of insecticides [9]. TFB is a polyphagous insect pest and is mostly prevalent round the year. Therefore, it receives the insecticide pressure from the farmers on many crops like cotton, fodder and vegetables [10]. The indiscriminate and unadvised application of pesticides to control this pest resulted in multifaceted problems including the environmental pollution, pesticide residue accumulation in fruits and insect pest resistance towards the traditional synthetic chemicals [4,11-13]. Abbas, et al. (2015) [14] also tested different insecticides with novel mode of action against TFB for its successful management in the tomato crop at two locations in districts Lodhran and Bahawalnagar, Punjab, Pakistan. They reported that highest average mortality (89.36 and 85.09) was exhibited by Voliam Flexi (chlorantraniliprole+thiamethoxam). In order to search and recommend newer chemicals for the management of this disreputable insect pest, six new chemistry insecticides were tested by Babar, et al. (2016) [9]. Insecticides viz., spinetoram $12 \% \mathrm{SC}$ and spinosad $240 \mathrm{SC}$ proved to be most effective till the 7th day of insecticidal application under the field conditions. Chlorfenapyr is a pro-insecticide and its toxic form; CL 303268 uncouples oxidative phosphorylation in the mitochondria, which results in disruption of ATP production, loss of energy, cell dysfunction and subsequent death of the organism [15]. Emamectin benzoate forms a reservoir in the leaves by penetrating in the leaf tissues (translaminar absorption) and inhibits the muscle contraction upon engulfing by the insects; causing incessant flow of chlorine ions in the GABA and H-Glutamate receptor locates [16]. Spinosad is highly active, by both contact and ingestion and effects primarily by targeting binding sites on nicotinic acetylcholine receptors (nAChRs) of the insect nervous system that are dissimilar from those at which other insecticides are effective and secondarily effects as a Gamma-amino-butyric acid (GABA) neurotransmitter agonist $[17,18]$. Another class (Diamide) of insecticides such as flubendiamide and chlorantraniliprole, are actively used against lepidopteran pests with a novel mode of action, selectively to actuate the insect ryanodine receptor (RyR) [19].

The selected insecticides viz., chlorfenapyr (Pirate ${ }^{\circledR}$ 360SL), spinosad (Tracer ${ }^{\circledR}$ 240SC), chlorantraniliprole (Coragen ${ }^{\circledR} 20 \mathrm{SC}$ ), emamectin benzoate (Proclaim ${ }^{\circledR}$ 1.9EC) and flubendiamide (Belt ${ }^{\circledR} 480 \mathrm{SC}$ ) has been reported to be used against various insect pests especially $H$. armigera in tomato crop $[9,14,20,21]$.

Considering the problems developing from the overusing of insecticides, the present study was planned to conduct the field evaluation of some newer insecticides against $H$. armigera and their recommendations for application by the farmers. The biocidal effects of insecticides were observed by noting the pest infestation levels before and after conducting the insecticidal sprays and hence the insecticides with higher rate of pest population reduction are explained as the most suitable ones for including in the TFB management action plans.

\section{Materials and Methods}

\section{Experimental Area and Tested Insecticides}

The nursery of tomato (Rio Grande Early) were collected during November 27, 2014 from Ayub Agricultural Research Institute (AARI), Faisalabad, Pakistan and transplanted on $1.5 \mathrm{~m}$ wide beds in Research Area of Department of Entomology, University of Agriculture, Faisalabad, Pakistan. A layout bearing a plot size of $4.5 \times 21 \mathrm{~m} 2$ for each treatment was maintained in each plot with row to row $60 \mathrm{~cm}$ and plant to plant $45 \mathrm{~cm}$ distance. Locally recommended agronomic practices (manuring and irrigations) were performed to raise a uniform crop and no pest preventive measures were applied. Chlorfenapyr (Pirate ${ }^{\circledR}$ 360SL), emamectin benzoate (Proclaim $\AA$ 1.9EC), spinosad (Tracer $\AA 240 \mathrm{SC}$ ), flubendiamide (Belt $\AA$ 480SC) and chlorantraniliprole (Coragen ${ }^{\circledR}$ 20SC) were tested against tomato fruit borer H. armigera on tomato field crop during 2014-15at the experimental area, Department of Entomology, University 
of Agriculture, Faisalabad, Pakistan. The commercial formulations of the tested chemicals/insecticides were obtained from the respective formulators/distributors (Table 1). All the insecticides were applied in field as foliar application by using a hand operated Jacto Hydraulic Knapsack sprayer (Brazil) with a tank capacity of 16-liters sand fitted with a hollow cone nozzle. Insecticide was applied at the time when insect population reached above Economic Threshold Level (ETL) i.e., 5\% damaged fruit in tomato [22]. Two insecticide sprays (e.g., 1st in 25th April 2015 and 2nd in 10th May 2015) were conducted to determine the variation in insecticidal efficacy. The concentrations of insecticides were prepared by mixing the recommended dose of the formulated material in tape water as provided on the label by the manufacturers. The insecticide solutions were applied on the plant canopy till runoff with the help of a Hydraulic Knapsack sprayer. The experiment was conducted in Randomized Complete Block Design (RCBD) with five treatments and three replications.

\begin{tabular}{|c|c|c|c|c|}
\hline Insecticide Formulation & Active Ingredient & Chemical Group & Dose (ml/acre) & Formulator/ Distributor \\
\hline Pirate 360SL & Chlorfenapyr & Halogenated pyrroles & 70 & Swat Agrochemicals, Pakistan \\
\hline Proclaim 1.9EC & emamectin benzoate & Avermectin & 200 & Syngenta, Pakistan Ltd. \\
\hline Tracer 240SC & Spinosad & Spinosyn & 40 & $\begin{array}{c}\text { Dow Agro Sciences/ Arysta Life } \\
\text { Science Pakistan }\end{array}$ \\
\hline Belt 480SC & Flubendiamide & Diamide & 20 & Bayer Crop Sciences, Pakistan \\
\hline Coragen 20SC & Chlorantraniliprole & Diamide & 50 & Dupont Pakistan/ UDL Pakistan \\
\hline
\end{tabular}

Table 1: Details of tested insecticides used against tomato fruit borer in tomato crop during the $1^{\text {st }}$ and $2^{\text {nd }}$ spray (dates) at the research area of University of Agriculture, Faisalabad, Pakistan.

\section{Sampling}

Insect pest surveillance was conducted weekly to observe the pest population establishment in the selected field. The observations on the pest infestation after 1st spray were recorded on April 28th, 30th, May 2nd, and May 4th2015and after 2 nd spray on May $13^{\text {th }}, 15^{\text {th }}, 17^{\text {th }}$ and $19^{\text {th }} 2015$. Counting of fruit borer from tomato crop was done from 15 randomly selected plants from each treatment starting from top to bottom. The percentage infestation and percentage reduction were then calculated by the given below formulae:

Percent $(\%)$ Infestation $=($ Infested Fruits $/$ Total Number of Fruits)X 100 Percent(\%)

Pest Reduction $=($ Pretreatment Pest Population-Post treatment Pest Population)/Pretreatment Pest Population) X 100

\section{Data Analysis}

The data regarding the Percentage Infestation and Percentage Reduction of the Pest were analyzed for variance to determine the parameters of significance and mean values for the insecticidal treatments. The significantly mean values were compared with Tukey's significant difference [9]. In order to explain the variation in means along with standard error and showing the differences in the treatments, graphs were prepared in Microsoft Excel, 2016. The regression equation and $\mathrm{R}^{2}$ values were also determined using Microsoft Excel to represent the effectivity of insecticides with the passage of time after treatment application.

\section{Results}

\section{Effectivity of Different Insecticide Formulations after $1^{\text {st }}$ Spray}

The results presented revealed that the effectiveness of all the insecticide treatments was significantly variable till the 9th day of treatment application (Figure 1). Percent infestation \% of TFB revealed that spinosad was most effective insecticide with minimum infestation $(16.22 \%)$ after 3 days of treatment application. This effectiveness was followed by the plots treated with flubendiamide $\quad(18.19 \pm 0.86 \%)$, chlorantraniliprole $(20.21 \pm 1.07 \%)$, chlorfenapyr $(21.50 \pm 0.73 \%)$ and emamectin benzoate $(25.18 \pm 1.13 \%)$ respectively. While, maximum infestation was recorded where no control measure was applied (check treatment), i.e., $33.12 \pm 1.35 \%$. After 3rd day of insecticide application, population reduction (\%) of TFB (Figure 2) revealed that maximum reduction of tomato fruit borer was recorded where spinosasd was applied i.e. $51.00 \pm 1.24 \%$, followed by flubendiamide $\quad(45.10 \pm 1.11 \%)$, chlorantraniliprole $(39.01 \pm 1.73 \%)$ and chlorfenapyr $(35.04 \pm 0.57 \%)$ respectively. While minimum population reduction was recorded where emamectin benzoate was applied i.e., $23.98 \pm 1.12 \%$. Minimum infestation by the TFB was noted in the plots treated with flubendiamide and spinosad 
were applied i.e. $10.15 \pm 0.42$ and $11.89 \pm 0.33 \%$, followed by chlorantraniliprole $(17.66 \pm 0.51 \%)$, chlorfenapyr $(19.79 \pm 1.05 \%)$ and emamectin benzoate $(21.12 \pm 0.74 \%)$ respectively on the 5th day of data recording after insecticidal spray. However, maximum pest reduction was recorded in the plots treated with flubendiamide $(70.12 \pm 1.80 \%)$, followed by and Tracer $(65.05 \pm 1.16 \%)$, chlorantraniliprole $(48.14 \pm 1.11 \%)$ and chlorfenapyr $(42.00 \pm 1.20 \%)$ respectively (Figures $2 \& 3)$. After 7 days of insecticidal application minimum infestation of the pest was recorded in the plots treated with chlorantraniliprole and flubendiamide $(5.63 \pm 0.41$ and $6.05 \pm 0.16 \%$, respectively) followed by, spinosad
(6.90 $\pm 0.98 \%)$,chlorfenapyr $(8.30 \pm 0.31 \%)$ and emamectin benzoate $(9.06 \pm 0.25 \%)$ respectively. It can be narrated from the data presented in the Figures $2 \& 3$ that the effectiveness of chlorfenapyr, emamectin benzoate, Spinosad and flubendiamide was increased while that of chlorantraniliprole was decreased after 7 days of insecticide spray. Minimum infestation of tomato fruit borer was recorded after 9 days of insecticide spray in plots where flubendiamide was applied $(3.40 \pm 0.79 \%)$, followed by Spinosad $(4.60 \pm 0.69 \%)$, chlorfenapyr $(7.14 \pm 0.45 \%)$, chlorantraniliprole $(7.59 \pm 0.68 \%)$ and emamectin benzoate $(8.41 \pm 0.47 \%)$, respectively.

Figure 1: Percent infestation of Tomato Fruit Borer after 1st Spray of chlorfenapyr, emamectin benzoate, spinosad, flubendiamide and chlorantraniliprole conducted on (date) at the research area of University of Agriculture, Faisalabad, Pakistan. The mean values were compared with Tukey's significant difference at 5\% probability. Dark Grey $=3$ Days after Insecticides Application, Light Grey $=5$ Days after Insecticides Application, Grey $=7$ Days after Insecticides Application and Black $=9$ Days after Insecticides Application.

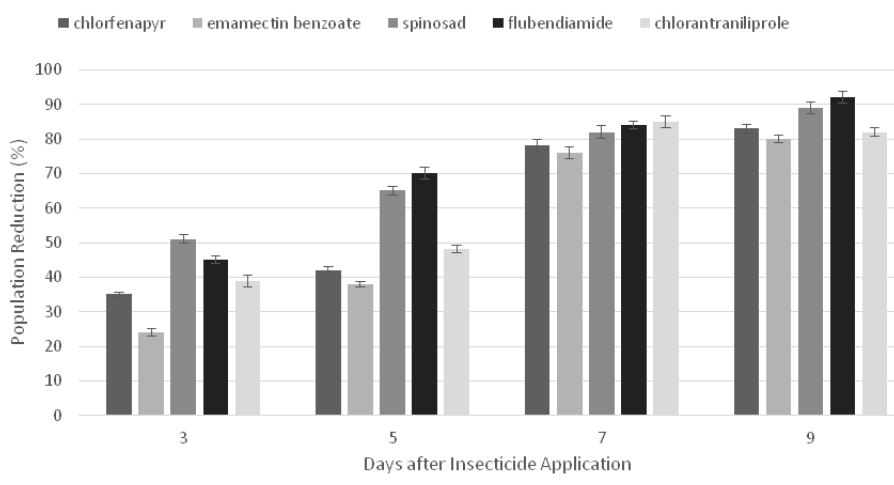

Figure 2: Percent population reduction of Tomato Fruit Borer after 1st Spray of chlorfenapyr, emamectin benzoate, spinosad, flubendiamide and chlorantraniliprole conducted on (date) at the research area of University of Agriculture, Faisalabad, Pakistan. The mean values were compared with Tukey's significant difference at $5 \%$ probability. 


\section{International Journal of Zoology and Animal Biology}

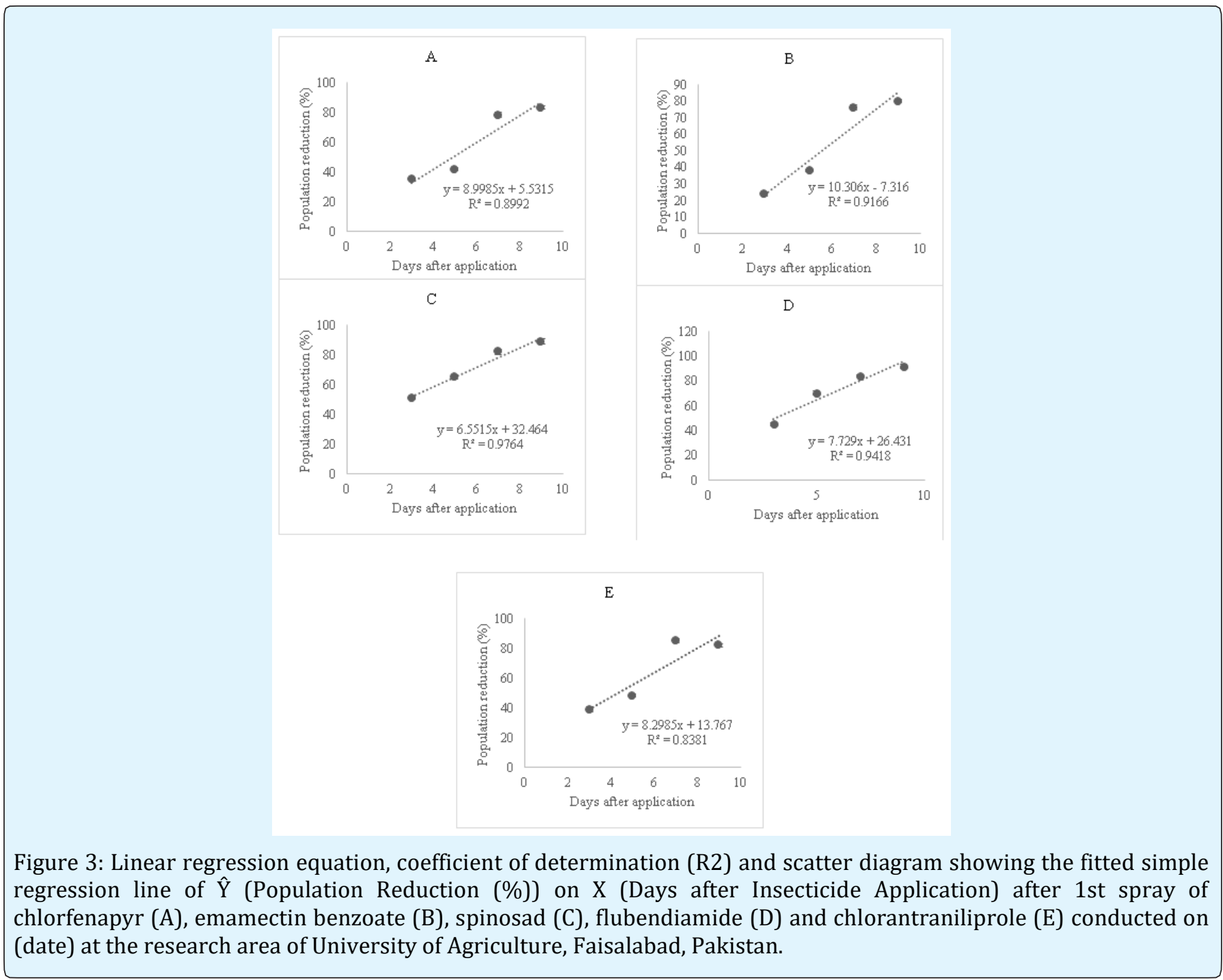

\section{Effectivity of Different Insecticide Formulations after $2^{\text {nd }}$ Spray}

After 2nd spray which was conducted when the TFB population reached beyond the economic threshold level; the mean percentage infestation of the pest was recorded after different time intervals from the day of insecticide application. The same insecticides viz. Pirate 360SL (chlorfenapyr), Proclaim 1.9EC (emamectin benzoate), Tracer 240SC (spinosad), Belt 480SC (flubendiamide) and Coragen 20SC (chlorantraniliprole) were sprayed in the already selected plots. The observations in all plots treated with different insecticides varied significantly (Figures 4-6). After 3 days of application, the mean percentage infestation data revealed that Spinosad was proved most efficient insecticide with minimum infestation $16.44 \pm 1.16 \%$ and a pest reduction of $53.03 \pm 1.74 \%$. These observations regarding pest infestation (\%) were followed by flubendiamide $(17.80 \pm 1.09 \%)$, chlorantraniliprole $(20.46 \pm 0.82 \%)$, chlorfenapyr $(23.40 \pm 0.93 \%)$ and emamectin benzoate $(25.49 \pm 1.40 \%)$ respectively. While minimum pest reduction $(27.11 \pm 1.21 \%)$ was recorded in plots where emamectin benzoate was applied. After 5 days of 2 nd insecticide spray, minimum infestation of tomato fruit borer was recorded where flubendiamide and spinosad were applied i.e., $11.12 \pm 0.47$ and $12.72 \pm 0.69 \%$ with a pest reduction of $72.04 \pm 1.15$ and $68.02 \pm 1.72 \%$, respectively. A maximum level of infestation $(24.28 \pm 0.67 \%)$ was observed in the plots treated with 
emamectin benzoate after control treatment with minimum pest reduction of $39.00 \pm 1.15 \%$. While maximum infestation was recorded where no control measure was applied (check treatment) i.e., 39.82 $1.06 \%$. After 7days of application, minimum infestation of TFB was recorded where chlorantraniliprole was applied i.e. $4.75 \pm 0.38 \%$, followed by flubendiamide $(6.05 \pm 0.59 \%)$, Spinosad (6.94 $\pm 0.73 \%)$, chlorfenapyr $(8.38 \pm 0.69 \%)$ and emamectin benzoate $(11.29 \pm 0.49 \%)$ respectively. While the observations noted on the $9^{\text {th }}$ day of application revealed that the effectiveness of chlorfenapyr, emamectin benzoate, Spinosasd and flubendiamide was increased while chlorantraniliprole was decreased. Minimum infestation $(5.00 \pm 0.70 \%)$ of tomato fruit borer was recorded in plots sprayed with flubendiamide with a maximum pest population reduction of $90.02 \pm 1.74 \%$.

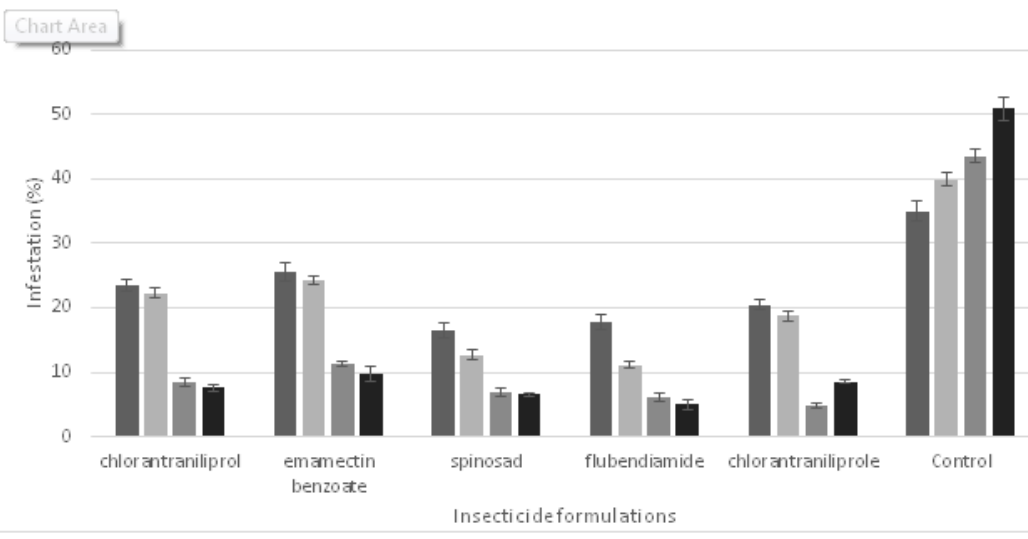

Figure 4: Percent infestation of Tomato Fruit Borer after 2nd Spray of chlorfenapyr, emamectin benzoate, spinosad, flubendiamide and chlorantraniliprole conducted on (date) at the research area of University of Agriculture, Faisalabad, Pakistan. The mean values were compared with Tukey's significant difference at 5\% probability. Dark Grey = 3 Days after Insecticides Application, Light Grey = 5 Days after Insecticides Application, Grey = 7 Days after Insecticides Application and Black = 9 Days after Insecticides Application.

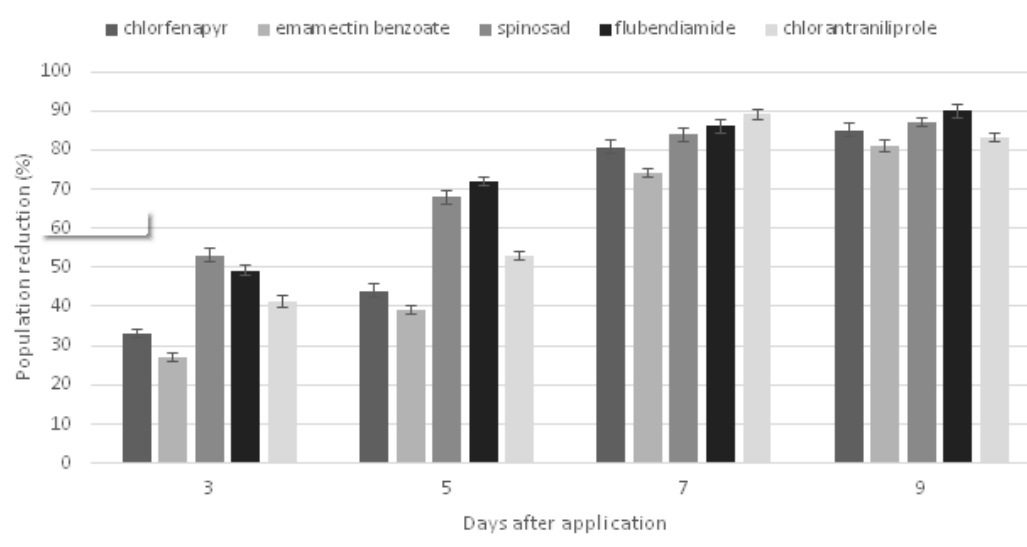

Figure 5: Percent population reduction of Tomato Fruit Borer after 2nd Spray of chlorfenapyr, emamectin benzoate, spinosad, flubendiamide and chlorantraniliprole conducted on (date) at the research area of University of Agriculture, Faisalabad, Pakistan. The mean values were compared with Tukey's significant difference at 5\% probability. 


\section{International Journal of Zoology and Animal Biology}

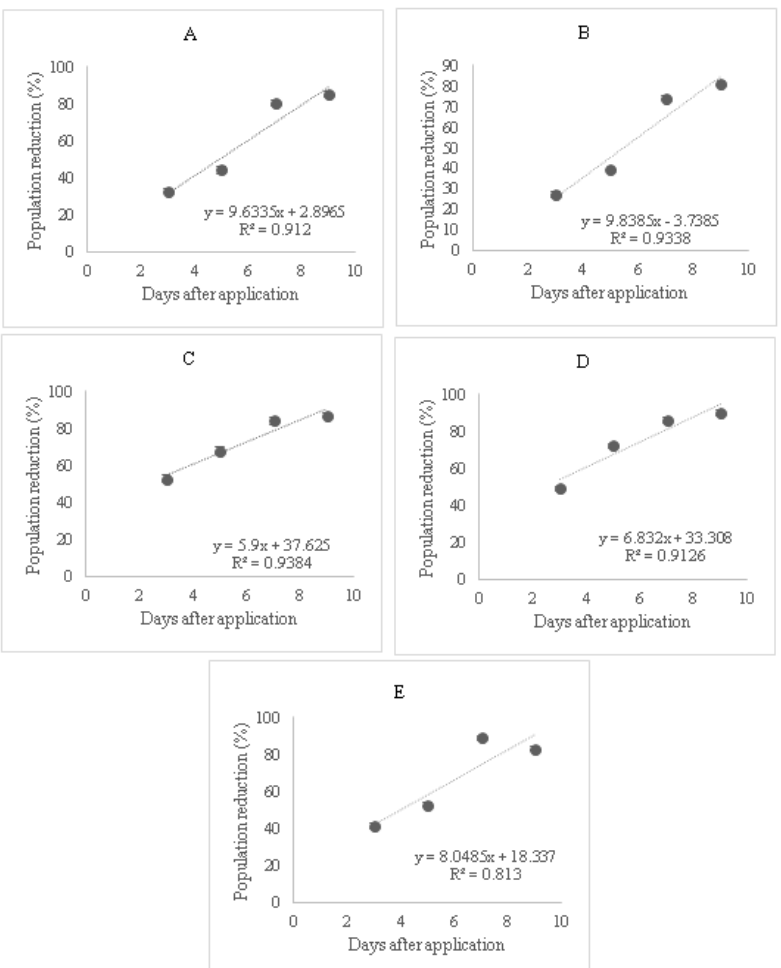

Figure 6: Linear regression equation, coefficient of determination (R2) and scatter diagram showing the fitted simple regression line of $\hat{Y}$ (Population Reduction (\%)) on $X$ (Days after Insecticide Application) after 2nd sprayofchlorfenapyr (A), emamectin benzoate (B), spinosad (C), flubendiamide (D) and chlorantraniliprole (E) conducted on (date) at the research area of University of Agriculture, Faisalabad, Pakistan.

\section{Discussion}

Five insecticides viz., Pirate 360SL (chlorfenapyr), Proclaim 1.9EC (emamectin benzoate), Tracer 240SC (spinosad), Belt 480SC (flubendiamide) and Coragen 20SC (chlorantraniliprole) at the rate of 70, 200, 40, 20 and 50 $\mathrm{ml}$ per acre, respectively were sprayed on tomato (variety Rio Grande early) when infestation of TFB reached beyond economic threshold level (ETL). Insecticide formulations were applied for two times in total and data for infestation (\%) and TFB population reduction were observed at various time intervals to see their comparative efficacy. The trial was laid out in randomized complete block design (RCBD) with three replications at the experimental area of Entomology Department, University of Agriculture, Faisalabad, Pakistan. The data regarding percentage infestation of TFB were recorded from each plot 3, 5, 7 and 9 days after each spray from 15 plants randomly in each plot. The findings of present study revealed that all the insecticidal treatments gave significant results regarding their effectivity even till the prolonged exposure time period. The effectivity of all treatment varied significantly at different time interval but in overall, results showed that minimum infestation and maximum reduction of tomato fruit borer was recorded where flubendiamide (Belt 480SC) was applied. This effectivity was followed by the plots treated with spinosad (Tracer 240SC), chlorantraniliprole (Coragen 20SC), chlorfenapyr (Pirate 360SL) and emamectin benzoate (Proclaim 1.9EC) respectively.

Results of our experiments match with those of Gadhiya, et al. [3], who tested different insecticides viz. emamectin benzoate, thiodicarb, indoxacarb, spinosad, novaluron, lufeneuron, flubendiamide, chlorantraniliprole and metaflumizone against fruit borer and concluded that flubendiamide, chlorantraniliprole, spinosad and emamectin benzoate were highly effective against fruit borer and statistically at par with each other. These findings are in conformity with those of Jat, et al. [23] they 


\section{International Journal of Zoology and Animal Biology}

tested bio pesticides and newer insecticides against fruit borer on tomato under field conditions and reported that flubendiamide was found significantly most effective, which caused highest mean reduction of population of tomato fruit borer among all insecticides followed by spinosad. Same kind of results were concluded by Shivanna, et al. [24] they tested different synthetic insecticides and biological extracts against fruit borer and reported minimum percentage infestation of tomato fruit borer was observed in flubendiamide followed by novaluran and spinosad respectively.

Our results were also confirmed by previous studies reporting efficacy of different insecticides against tomato fruit borer and concluding that flubendiamide, spinosad, emamectin benzoate and chlorantraniliprole were very effective insecticides against tomato fruit borer and gave maximum results [3,21,23-28]. Furthermore, spinosad is also very effective treatment in present study which is also supported by previous scientists. Ghosh, et al. [29] performed an experiment to check the effectiveness of various insecticides against tomato fruit borer using spinosad, Lambda cyhalothrin, Quinalphos and Cypermethrin and concluded that spinosad was most efficient against tomato fruit borer than other used pesticides.

Present results also supported by Sreekanth, et al. [30] who performed an experiment to check the comparative effectiveness of various insecticides against fruit borer and reported that spinosad proved superior insecticide against tomato fruit borer. Gandhi, et al. [31] also tested five insecticides viz, spinosad, cypermethrin, novaluran, azadirachtin and Bacillus thringiensis against $H$. armigeraand reported that spinosad proved as a superior insecticide followed by novaluran and azardirachtin. Same kind of results were reported by Roopa, et al. [32] they tested some selected insecticides against fruit borer and reported that spinosad was most effective insecticide in reducing pest population and highest yield of the crop was observed in spinosad treated plots.

Experiments performed to determine the comparative efficacy of different insecticides belonging to the groups with novel mode of action against tomato fruit borer (TFB) also reported that flubendiamide, spinosad, emamectin benzoate and chlorfenapyr were the most effective insecticides than other insecticides used against tomato fruit borer [3,9,14,16,20,25,26,28,33-37].

Tomato fruit borer is a severe pest of tomato which causes significant yield losses of tomato due to its attack which also affect its quality as well. On the basis of the findings of these experiments, a rotational application of the more effective insecticides viz, flubendiamide (Belt 480SC), spinosad (Tracer 240SC), chlorantraniliprole (Coragen 20SC), chlorfenapyr (Pirate 360SL) and emamectin benzoate should be conducted to get an effective control of TFB ( $H$. armigera). Therefore, based on the effectivity of these insecticides, they are strongly recommended to be included in the Integrated Pest Management Program for TFB control.

\section{References}

1. Gerald B, Frank Z (2005) Tomato vegetable insect pest management. In: Rick F, (Ed.), USA, Meister Media Worldwide, pp: 124-142.

2. GOP (2015) Working Paper, Meeting of the Federal Committee on Agriculture (FCA), Kharif Season 201516. Ministry of National Food Security and Research, pp: 1-45.

3. Gadhiya HA, Barad PK, Bhut JB (2014) Effectiveness of synthetic insecticides against Helicoverpa armigera (hubner) hardwick and Spodoptera litura (Fabricius) infesting groundnut. The Bioscan 9(1): 23-26.

4. Meena LK, Raju SVS (2014) Bio-efficacy of newer insecticides against tomato fruit borer, Helicoverpa armigera (Hubner) on tomato, Lycopersicon esculentum Mill under field conditions. The Bioscan 9(1): 347-350.

5. Selvanarayanan V, Narayanasamy P (2006) Factors of resistance in tomato accessions against the fruit worm, Helicoverpa armigera (Hubner). Crop Protection 25(10): 1075-1079.

6. Dhandapani N, Umeshchandra RS, Murugan M (2003) Bio-Intensive Pest Management (BIPM) in major vegetable crops: An Indian perspective. Food Agriculture and Environment 1(2): 333-339.

7. Latif M, Aheer GM, Saeed M (1997) Quantitative Losses in Tomato Fruits by Heliothis armigera Hb. Abstrscted in PM-9, Third International Congress of Entomological Science, Pakistan Entomological Society, March 18-20, 1997. National Agricultural Research Center, Islamabad.

8. Inayatullah M (2007) Biological control of tomato fruit worm (Helicoverpa armigera) using egg parasitoid Trichogramma chilonis 


\section{International Journal of Zoology and Animal Biology}

(Trichogrammatidae: Hymenoptera) and Chrysoperla carnea (Chrysopidae: Neuroptera). First Annual Technical Report, HEC Funded Project, pp: 99.

9. Babar TK, Hasnain M, Aslam A, Ali Q, Ahmad KJ, et al. (2016) Comparative bioefficacy of newer insecticides against tomato fruit borer, Helicoverpa armigera (Hubner) on tomato crop under field conditions. Pak Entomol 38(2): 115-122.

10. Shaheen N (2008) Is organic forming suitable solution for Pakistan. SDPI Research News Bulletin 15: 78-81.

11. Ahmad M, Arif MI, Ahmad Z (1999) Patterns of resistance to organophosphate insecticides in field populations of Helicoverpa armigera in Pakistan. Pesticide Science 55(6): 626-632.

12. Ahmad M, Arif MI, Ahmad Z (2001) Resistance to carbamate insecticides in Helicoverpa armigera (Lepidoptera: Noctuidae) in Pakistan. Crop Protection 20: 427-432.

13. Qayyum MA, Wakil W, Arif MJ, Sahi ST, Saeed NA, et al. (2015) Multiple Resistance against formulated organophosphate, pyrethroids and newer-chemistry insecticides in populations of Helicoverpa armigera (Lepidoptera: Noctuidae) from Pakistan. J Econ Entomol 108(1): 286-293.

14. Abbas G, Hassan N, Farhan M, Haq I, Karar H (2015) Effect of selected insecticides on Helicoverpa armigera Hubner (Lepidoptera: Noctuidae) on Tomato (Lycopersicon esculentum Miller) and their successful management. Advances in Entomology 3(1): 16-23.

15. Raghavendra K, Barik TK, Sharma P, Bhatt RM, Srivastava HC, et al. (2011) Chlorfenapyr: a new insecticide with novel mode of action can control pyrethroid resistant malaria vectors. Malaria J 10: 16.

16. Fanigliulo A, Sacchetti M (2008) Emamectin benzoate: a new insecticide against Helicoverpa armigera. Communication Agriculture Applied Biological Sciences 73(3): 651-653.

17. Qiao M, Snyder DE, Meyer J, Zimmerman AG, Gissendanner SJ, et al. (2007) Preliminary studies on the effectiveness of the novel pulicide, spinosad, for the treatment and control of fleas on dogs. Vet Parasitol 150(4): 345-351.
18. Hertlein M, Thompson GD, Subramanyam B, Athanassiou CG (2011) Spinosad: A new natural product for stored grain protection. Stored Products 47: 131-146.

19. Troczka BJ, Williamson MS, Field LM, Davies TGE (2016) Rapid selection for resistance to diamide insecticides in Plutella xylostella via specific amino acid polymorphisms in the ryanodine receptor. Neurotoxicology 60: 224-233.

20. Ambule AT, Radadia GG, Shinde CU, Patil DL (2015) Relative efficacy of newer insecticides against Helicoverpa armigera (Hubner) in tomato under South Gujarat condition. Int J Plant Protection 8(2): 250-255.

21. Hanafy HEM, El-Sayed W (2013) Efficacy of bio-and chemical insecticides in the control of Tuta absoluta (Meyrick) and Helicoverpa armigera (Hubner) infesting tomato plants. Australian Journal of Basic and Applied Sciences 7(2): 943-948.

22. GOP (2017) Economic threshold levels of insect pests. Directorate General of Pest Warning and Quality Control of Pesticides, Lahore.

23. Jat SK, Ameta OP (2013) Relative efficacy of Biopesticides and newer insecticides against Helicoverpa armigera (HUB.) in tomato. The Bioscan 8(2): 579-582.

24. Shivanna BK, Naik BG, Singh GD, Raja KN (2012) Impact of biopesticides on budworm incidence and its effect on yield in tobacco. International Journal of Life Science, Biotechnology and Pharmacology Research 1(1): 76-79.

25. Tatagar HM, Mohankumar HD, Prasad MS, Mesta RK (2009) Bio-efficacy of flubendiamide $20 \mathrm{WG}$ against chilli fruit borers, Helicoverpa armigera (Hub.) and Spodoptera litura (Fb.). Karnataka J Agric Sci 22(S3): 579-581.

26. Deshmukh SG, Sureja BV, Jethva DM, Chatar VP (2010) Field efficacy of different insecticides against Helicoverpa armigera (Hubner) infesting chickpea. Legume Research 33(4): 269-273.

27. Ghosal A, Chatterjee ML, Manna D (2012) Studies on some insecticides with novel mode of action for the management of tomato fruit borer (Helicoverpa armigera Hub.). J Crop and Weed 8(2): 126-129. 
28. Katroju RK, Cherukuri SR, Vemuri SB, Narasimha RK (2014) Bio-efficacy of insecticides against fruit borer (Helicoverpa armigera) in tomato (Lycopersicon esculentum). Int J Appl Biol and Pharmaceut Technol 5(1): 239-243.

29. Ghosh A, Chatterjee M, Roy A (2010) Bio-efficacy of spinosad against tomato fruit borer (Helicoverpa armigera Hub.) (Lepidoptera: Noctuidae) and its natural enemies. Journal of Horticulture and Forestry 2(5): 108-111.

30. Sreekanth M, Seshamahalakshmi M (2012) Studies on relative toxicity of biopesticides to Helicoverpa armigera (Hubner) and Maruca vitrata (Geyer) on pigeonpea (Cajanuscajan L.). J Biopest 5(2): 191-195.

31. Gandhi BK, Shekharappa Balikai RA (2013) Bio-efficacy of insecticides in management of Helicoverpa armigera (Hubner) in kharif sorghum. Annals of Plant Protection Sci 21(1): 83-86.

32. Roopa M, Kumar CTA (2014) Bio-efficacy of new insecticide molecules against capsicum fruit borer, Helicoverpa armigera (hubner). Global J Biol Agric Health Sci 3(3): 219-221.
33. Ahmad M, Arif MI, Ahmad Z (2003) Susceptibility of Helicoverpa armigera (Lepidoptera: Noctuidae) to new chemistries in Pakistan. Crop Protection 22: 539544.

34. Razaq M, Suhail A, Aslam M, Arif MJ, Saleem MA, et al.

35. Shah JA, Inayatullah M, Sohail K, Shah SF, Shah S, et al. (2013) Efficacy of botanical extracts and a chemical pesticide against tomato fruit worm, Helicoverpa armigera (Lepidoptera: Noctuidae). Sarhad Journal of Agriculture 29(1): 93-96.

36. Khorasiya SG, Vyas HJ, Jetha DM, Joshi PH (2014) Field efficacy of Helicoverpa armigera (Hübner) hardwick on pigeonpea. Int J Plant Protec 7(2): 325329.

37. Soliman MMM, Abdel-Moniem ASH, Abdel Raheem MA (2014) Impact of some insecticides and their mixtures on the population of tomato borers, Tuta absoluta (Meyrick) (Lepidoptera: Gelechiidae) and Helicoverpa armigera (Hübner) (Lepidoptera: Noctuidae) in tomato crop at Upper Egypt. Archi Phytopathol Pl Prot 4(14): 1764-1776. 